\title{
Comparison of materials for repair of cardiac defects
}

\author{
D. B. LONGMORE, W. A. COOK, B. A. JEPSON, \\ R. CURRAN, AND J . B. KINMONTH \\ From St. Thomas's Hospital Medical School, London, S.E.1
}

Many cardiac defects can be repaired by direct suture. Some septal defects and narrowings of the ventricular outflow tracts require the implantation of additional material. The qualities of the implanted material may need to differ according to the nature of the defect. If it is one involving the outer wall of the heart or great vessels the repair may be able to gain blood supply or support from the surrounding tissues. If, on the other hand, the defect is intracardiac, perhaps a large atrial or ventricular septal defect, it may be that the implanted material will need to lie with both its surfaces freely exposed to the blood. It must then rely upon its own strength and durability, together with any growth of host tissues that may occur from its periphery, in order to remain intact. It will not have the advantage of assistance or support from the host tissues on one of its surfaces, such as it might get if it were placed on the outer wall of the heart or great vessels.

It is difficult to test unsupported implants in the heart because artificially produced defects in the septa show a strong tendency to contract and obliterate. Defects in the walls of the heart or great vessels can be made in such a way that this tendency is overcome. The studies recorded herz are of materials implanted into such defects. They give direct data on the behaviour of supported implants but also less directly some knowledge as to how unsupported implants of different materials might behave.

\section{METHODS}

The dogs in this series were 62 mongrels of all ages varying in weight from $2 \cdot 2$ to $32.5 \mathrm{~kg}$., with an average of $14.6 \mathrm{~kg}$. Younger dogs were used for patching under hypothermia because they were less susceptible to ventricular fibrillation. Some small puppies were also used in open operations, using the pump oxygenator to gain additional experience in perfusion of small patients.

Most of the dogs were operated through a right thoracotomy in the bed of the fifth rib, which was found to be most satisfactory. In 20 of these, extra- corporeal circulation was used with a variety of apparatus. The early cases were done with a Melrose- 0 N.E.P. pump oxygenator, and the later cases with an Osborn-Bramson-Gerbode rotating disc oxy- $\vec{c}$ genator in combination with either a 'Mono' pump $\mathbb{D}$ or a roller pump. The remaining cases were done under hypothermia and inflow occlusion, applying $\frac{\mathbb{D}}{3}$ the patch to the exterior of the pulmonary outflow tract and resecting the myocardium and pulmonary artery beneath through a gap left at the myocardial $\vec{O}$ end. In all of the later cases the pericardium was closed over the patch to give it support and to assist in haemostasis. Figure 1 shows the position in which the patch was inserted in the heart. In all cases a

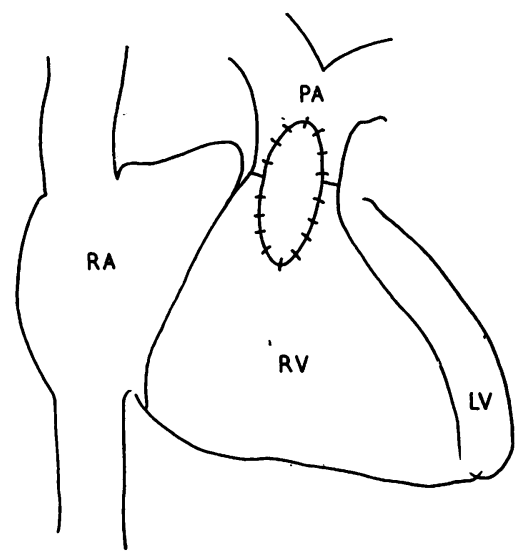

FIG. 1. The site of insertion of the patches which lie across the line of the pulmonary valve. The pulmonary valve wasos resected.

substantial amount of pulmonary valve was excised together with a 4 by $2 \mathrm{~cm}$. area of pulmonary artery and right ventricle to ensure incompetence of the $\frac{C}{\Phi}$ valve. This was necessary to prevent shrinkage of $\mathscr{D}$ the patch which always occurs in the ventricle if the pulmonary valve remains competent.

PATCh MATERIALS Materials used for vascular repair are conveniently classified as (1) autografts, consisting of tissues from the host animal itself; (2) homografts, consisting of tissues taken from other animals $O$ 
of the same species; (3) heterografts, consisting of tissue from a donor of some species different from the host; and (4) prostheses, which are non-biologic materials usually made of woven plastic cloth. Autografts were made from the dog's own pericardium. This was taken from low down, and the pericardium was reconstituted at the end of the operation covering the patch and leaving only a small defect over the apex of the ventricles which did not allow herniation of the heart. The suture-holding properties of all the materials were assessed by measuring the weight at which a $3 / 0$ atraumatic silk suture placed $1 \mathrm{~mm}$. from the edge of the material would pull out. This was done by a method similar to that described by Warwick-Brown (1954). The strengths for different materials compared with the cardiac wall are shown in Table $I$.

T A B L E I

STRENGTHS OF MATERIALS BEFORE OPERATION

\begin{tabular}{|c|c|}
\hline Material & Pull-out Strength (g.) \\
\hline Ventricular wall (full thickness, $\operatorname{dog} R V$ ) & 700 \\
\hline $\begin{array}{l}\text { Pericardium (fresh canine) } \\
\text { Pericardium (H.CHO canine) } \\
\text { Inferior vena cava (H.CHO canine) } \\
\text { Pericardium (H.CHO human) } \\
\text { Pericardium (fresh human, adult) } \\
\text { Terylene C828 } \quad \text {.. } \quad . .\end{array}$ & $\begin{array}{l}124 \\
177 \\
266 \\
443 \\
692 \\
740\end{array}$ \\
\hline
\end{tabular}

Each figure is the mean of 12 measurements.

The materials tested for suitability as patches were: (1) as autograft, fresh canine pericardium; (2) as homograft, formalin-preserved canine inferior vena cava ; (3) as heterograft, formalin-preserved human pericardium ; (4) as prosthesis, C828 terylene ('Dacron') Taffeta.' The preserved animal tissue was extended on a rigid plate of plastic and stored in $4 \%$ formol saline with a $p H$ range of 5.6 to 6.74 , which is reported to cause the least tendency to calcification (Peirce, Rheinlander, Moritz, Gross, and Merrill, 1949 ; Kinmonth, 1960). Before insertion the preserved grafts were washed in sterile saline and were used with the endothelial or serous surface towards the lumen.

\section{RESULTS}

The dogs were sacrificed at varying intervals to provide at least two of each type of patch at three, six, and nine months, with some left for longer periods. The homograft group, using formalin-preserved canine inferior vena cava, were all macroscopically successful with no evidence of dilatation or contraction, a smooth shiny surface inside, and a densely adherent pericardium on the exterior surface of the patch. Microscopically, however, there was evidence of hyaline

1 Woven by Joshua Hoyle \& Sons Ltd., Manchester. This material is made of 75 denier fibre. The loomstate construction of $\mathbf{C 8 2 8}$ is 156 warp, 90 weft. It is known in the U.S.A. as Dacron.

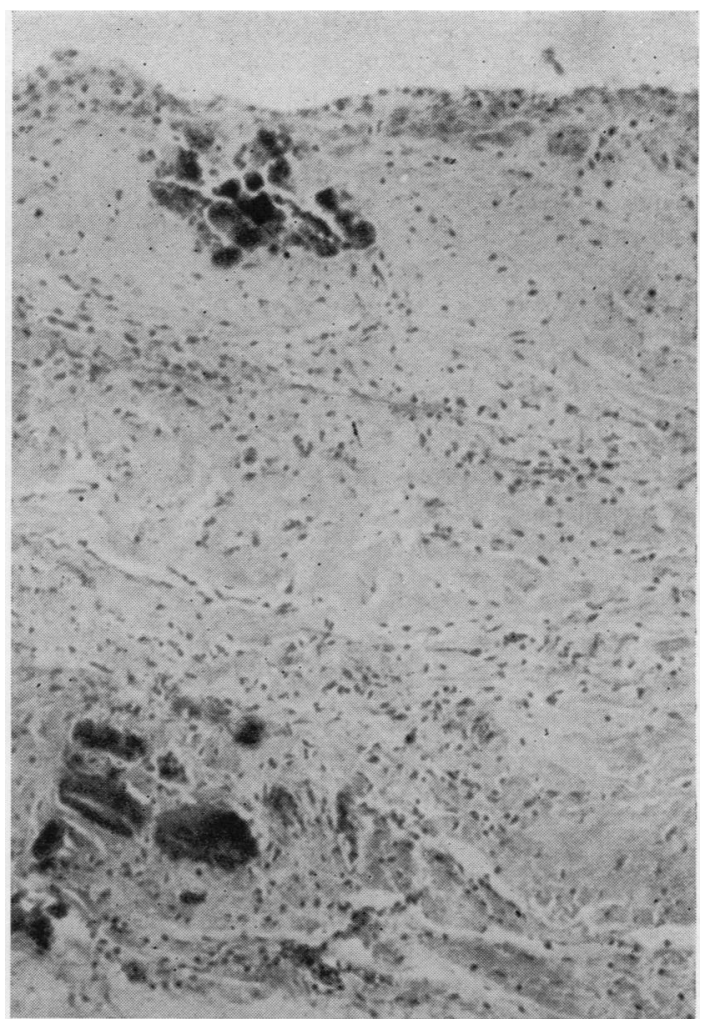

FIG. 2. A section through a heterograft of human inferior vena cava which has been in place for five months. Masses of fibrous tissue and some cartilage may be seen.

degeneration, elastic tissue fragmentation, lysis, and calcification of the graft (Fig. 2). Although there was good fibrous tissue replacement and support, it appears to us, as it has to others (Creech, 1959), that this degenerative situation might represent an intrinsic weakness.

The group with heterografts of human pericardium also had a fairly satisfactory macroscopic appearance, but on microscopic examination the cases sacrificed at three months showed marked foreign-body reaction and lysis of the graft by histiocytes (Fig. 3), while those sacrificed at nine months had complete resorption of the graft elements with replacement by fibrous tissue containing cartilage, calcium, and signs of abscess formation.

The terylene autografts were very successful. Macroscopically they were covered by a thick layer of smooth, shiny fibrous tissue on the internal surface, and a strong layer of fibrous tissue on the external surface, probably proliferated by the densely adherent pericardium. Microscopi- 
cally the material remained unchanged but showed good invasion of its interstices, good seating at the graft host junction, and strong, well-vascularized fibrous tissue support on both sides (Figs. 4 and 5).

The autogenous pericardial patches were all macroscopically successful, and there were no cases of aneurysmal dilatation of the patch. Microscopically they showed no degenerative changes, but neither did they show formation of additional fibrous tissue. They looked virtually unchanged. The autogenous patches were much more difficult to manipulate and to make bloodtight than any of the other materials, and many dogs failed to survive operation on this account. Once they were in place and haemostasis was secured, they seemed to function as well as the other materials.

The tear-out strengths are shown in Table II.

The suture 'pull-out' strengths recorded in Table II all refer to the patch material itself measured after it was denuded of overlying pericardium, lung, or other tissue.
It will be seen that autogenous pericardium started with a low 'pull-out' strength for sutures but increased to a mean of $548 \mathrm{~g}$. in dogs sacrificed six to 13 months after it had been inserted. The preserved homograft material came next, attaining a mean of $812 \mathrm{~g}$. after implantation for similar periods. Both heterografts and prostheses attained strengths greater than could be measured by this method as they became stronger than the suture material used.

When both the strength attained by the different materials and the microscopic appearances are

TABLE II

CHANGES IN STRENGTH OF CARDIAC PATCHES

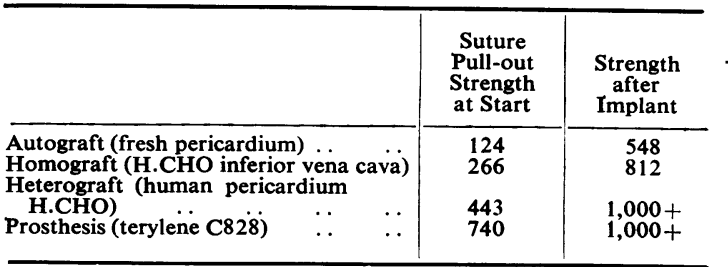

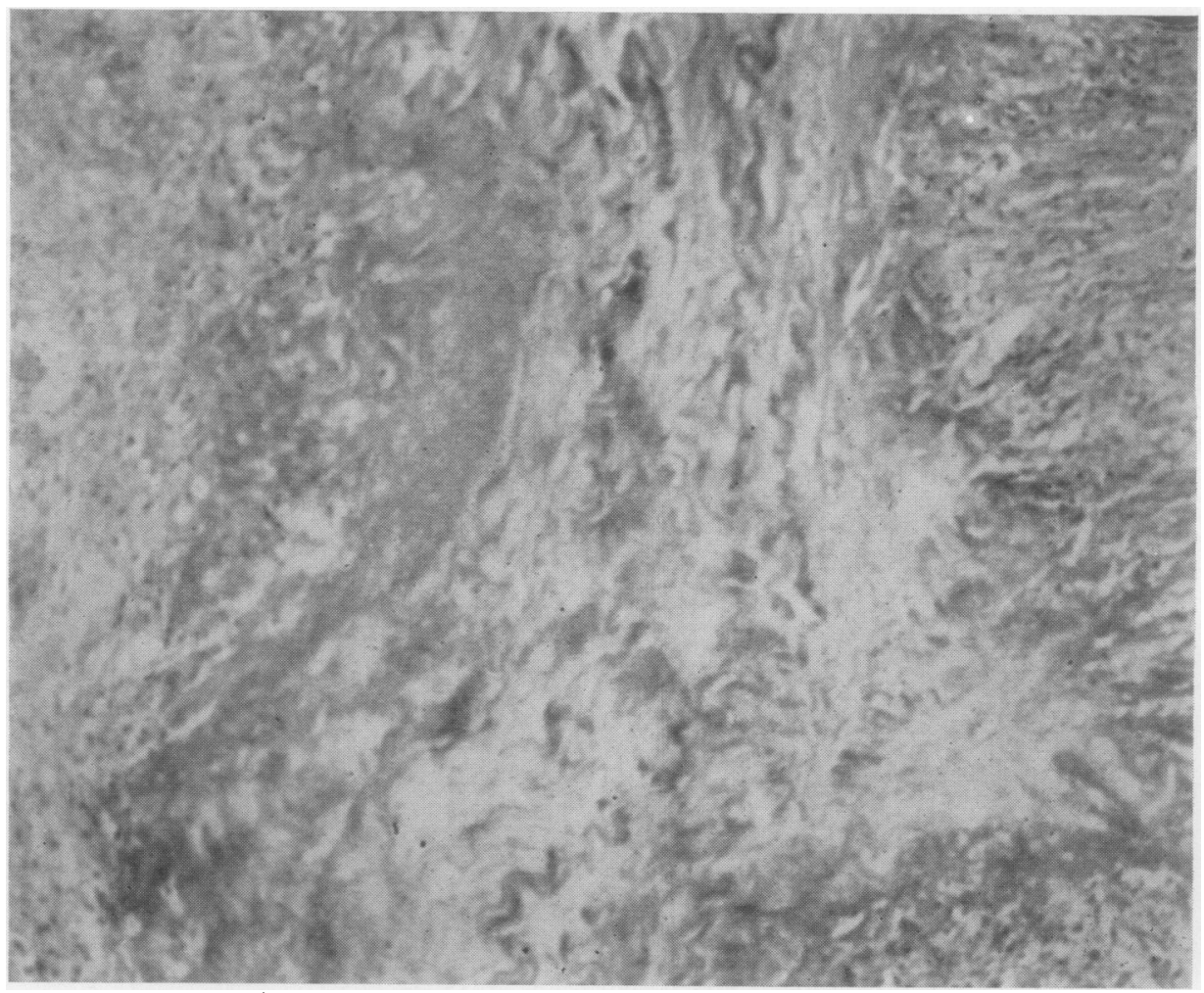

FIG. 3. Heterograft with formalin-preserved human pericardium at three months. Intense fibrous tissue formation may be seen. 


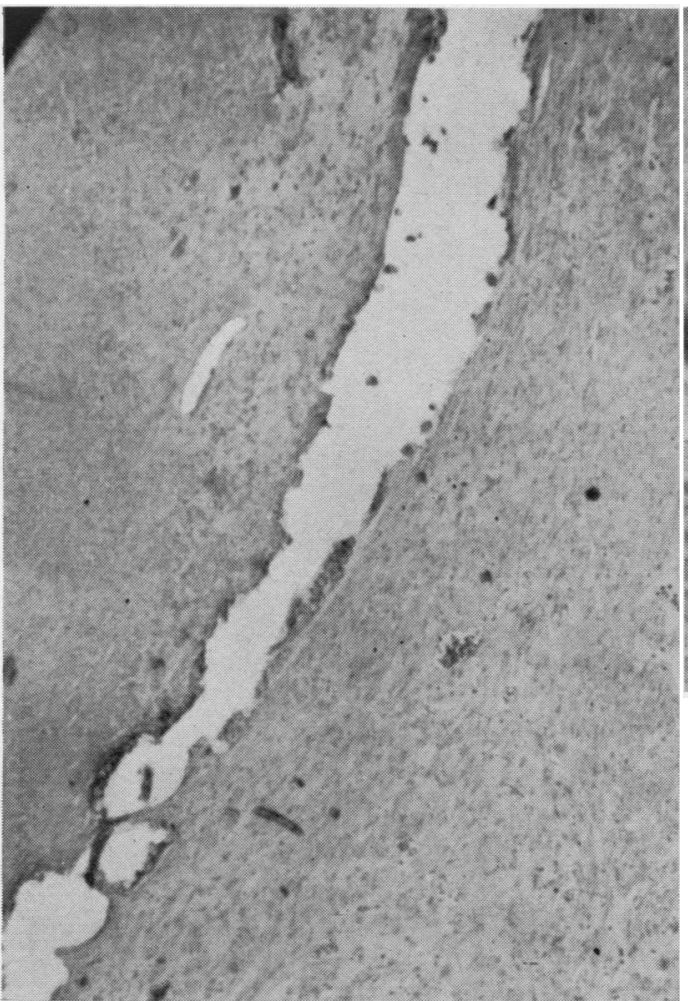

FIG. 4

considered together the terylene cloth seems best. Heterograft and homograft, although strong, showed degenerative changes which might over very long periods have caused trouble. Autogenous pericardium, although slightly weaker, showed no degeneration, but neither did it show evidence of growth of new fibrous tissue.

If these findings are to be used as a guide in clinical practice, it might be concluded that terylene cloth would be the stronger and safer material to use for a patch that might have to remain unsupported, as for example in a large septal defect. For patches in the wall of the heart, where additional strength may be rapidly gained from the adherence of adjacent structures such as the patient's own pericardium, the other materials tested would be adequate. Autogenous pericardium is convenient to procure. It has the extra virtue that it is, unlike cloth, non-porous and less likely to allow troublesome oozing. It would be preferable to use, for example, to enlarge the pulmonary outflow tract should this need to be done in a patient with Fallot's tetra$\operatorname{logy}$ or a similar deformity.

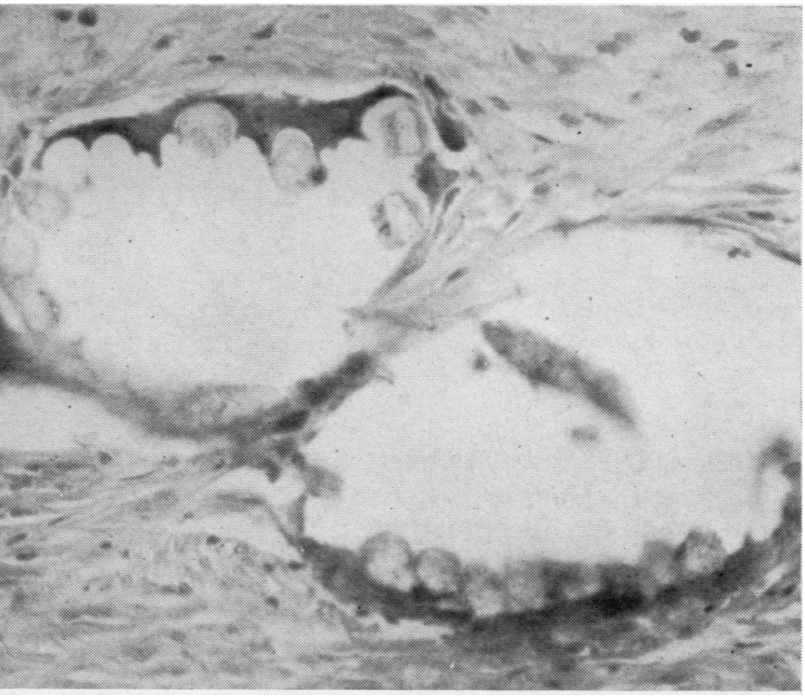

FIG. 5

FIG. 4. A low-power view cut across a C828 terylene patch showing that even as early as two months after implantation there is excellent fibrous tissue reinforcement on both sides of the cloth.

FIG. 5. Shows some fibres of the terylene cloth still in place. Most of the cloth had to be removed in order to cut the section. The cloth is surrounded by strong fibrous tissue with no areas of degeneration.

\section{CONCLUSIONS}

These experiments suggest that prosthetic material produces the strongest repair and might be best for use as unsupported patches.

Autogenous pericardium also produced good repairs but was less strong than cloth. It should be adequate for supported repairs in the external wall of the heart.

We should like to thank the technical staff of the Surgical Professorial Unit of St. Thomas's Hospital for their part in the work, and also Professor Curran's technical staff for their assistance in the preparation of the specimens. We should also like to thank Mr. Brandon and the staff of the Photographic Department of St. Thomas's Hospital for the monochrome reproductions of the photomicrographs.

\section{REFERENCES}

Creech, O., Jr., in discussion of Humphries A. W., Hawk, W. A. de Wolfe, V. G., and Le Fevre, F. A. (1959). C̈linicopathologic observations on the fate of arterial freeze-dried homografts. Surgery, 45, 69.

Kinmonth, J. B. (1960). Some aspects of cardiovascular surgery. J. roy. Coll. Surg. Edinb., 5, 287.

Peirce, E. C., II, Rheinlander, H. F., Moritz, A. R., Gross, R. E., and Merrill, K., Jr. (1949) Transplantation of aortic segments fixed in $4 \%$ neutral formalin. Report of experiments in dogs. Amer. $J$. Surg., 78, 314.

Warwick-Brown, R. (1954). Some physical properties of vascular grafts. Brit. J. Surg., 42, 316. 